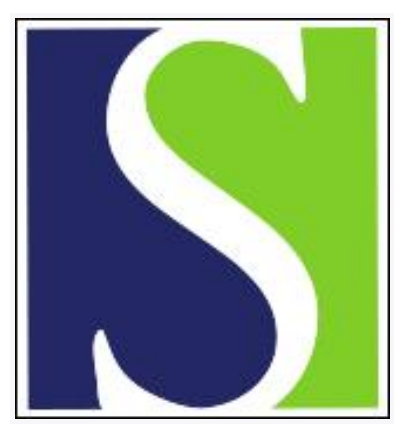

Scand J Work Environ Health 1984;10(1):51-55

https://doi.org/10.5271/sjweh.2363

Issue date: Feb 1984

A new method for the analysis of tetramethyllead in blood. by Andersson K, Nilsson CA, Nygren 0

This article in PubMed: www.ncbi.nlm.nih.gov/pubmed/6740277

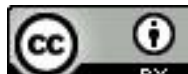




\title{
A new method for the analysis of tetramethyllead in blood
}

\author{
by Kurt Andersson, PhD, Carl-Axel Nilsson, PhD, Olle Nygren, BSc ${ }^{1}$
}

\begin{abstract}
ANDERSSON K, NILSSON C-A, NYGREN O. A new method for the analysis of tetramethyllead in blood. Scand $j$ work environ health 10 (1984) $51-55$. In this paper a method for the determination of alkyllead compounds in blood is described. The method is based on extraction of the alkyllead compounds into an organic solvent, followed by separation by high-resolution gas chromatography. A graphite-furnace atomic absorption spectrophotometer is used as the detector. A detection limit of 0.01 $\mu \mathrm{g} / \mathrm{ml}$ for tetramethyllead was obtained in blood samples. The method was used for the investigation of occupational exposure to tetramethyllead in gasoline. Blood samples from tank cleaners and gasoline pump servicemen showed detectable amounts of tetramethyllead. The reference group did not show any detectable levels of tetramethyllead.
\end{abstract}

Key terms: graphite-furnace atomic absorption spectrophotometry, high-resolution gas chromatography, organolead compounds, tetraalkyllead compounds, tetraethyllead.

Tetraalkyllead compounds have been used as antiknock additives in gasoline since 1921, after General Motors had discovered the effect of tetraethyllead. Today several groups are occupationally exposed to tetraalkyllead, for example, tank cleaners, garage workers, depot workers, and gasoline pump servicemen. Tetraalkyllead, which can penetrate the skin and be absorbed through the lungs, is considered to be about 10 times more toxic than inorganic lead. Dealkylation to trialkyllead salts occurs in the body, and these salts are the cause of the toxic reaction (6). Because of the higher toxicity of the organolead compounds, it is important to determine tetraalkyllead selectively in the presence of inorganic lead in biological materials. Normal levels of inorganic lead in human blood are $0.1-0.2 \mu \mathrm{g} / \mathrm{ml}(0.5-1.0 \mu \mathrm{mol} / 1)$. Hence a detection limit for tetraalkyllead lower than $0.01 \mu \mathrm{g} / \mathrm{ml}$ (as lead) is desirable in blood samples.

Currently used methods for blood lead analysis give only the total lead concentration and cannot discriminate between organic and inorganic lead. DeJonghe \& Adams have recently published a review (5) describing various methods of determining alkyllead compounds. Most of these methods deal with the analysis of tetraalkyllead in air samples or in

\footnotetext{
1 National Board of Occupational Safety and Health, Department of Occupational Health in Umeå, S-900 06 Umeả, Sweden.
}

Reprint requests to: $\mathrm{Mr} \mathrm{O}$ Nygren, National Board of Occupational Safety and Health, Department of Occupational Health in Umeå, Box 6104, S-900 06 Umeå, Sweden. gasoline. A few papers have also been published on the analysis of tetraalkyllead in biological materials $(1,2,4,7,11)$. Various analytical methods are presented in these publications. Solvent extraction, conversion of the organolead to inorganic lead, and spectrophotometric or atomic absorption determination have been used by some of the investigators ( 1 , $5)$. Others have used the cold-trap technique (2) or a heat desorber (3), both coupled to an atomic absorption spectrophotometer for the selective determination of the tetraalkyllead. Liquid chromatography has also been used for the separation of tetraalkyllead (9), but it is preferred for less volatile compounds. The most sensitive method seems however to be gas chromatography (GC) with atomic absorption spectrometry (AAS) as a lead-specific detector. DeJonghe \& Adams (5) used this method for the analysis of tetraalkyllead in ambient air and gasoline. Methods based on this technique for the determination of tetraalkyllead in biological materials have been published by Chau et al (2), Cruz et al (4), and Wong et al (11). However, as already stated, several of the methods used for the determination of tetraalkyllead in biological materials suffer from lack of sensitivity for the analysis of human blood samples. Some of the methods have other disadvantages, such as difficult or complex cleanup steps during sample preparation or a complicated analytical procedure. The present report introduces a method for the determination of tetramethyllead in blood with an adequate detection limit for blood samples of occupationally exposed persons. 


\section{Materials and methods}

\section{Chemicals and glassware}

All of the chemicals used were of an analytical grade, and water was purified in a Millipore R/Q Water Purifier. The solvents used for dilution and extraction were $\mathrm{n}$-hexane, diethyl ether, dichloromethane, benzene, n-heptane, undecane, and ethanol. A 0.4-g/1 gasoline standard was used as a stock solution for tetramethyllead. The stock solution was diluted in $\mathrm{n}$-heptane for the working standards and in ethanol for the blood spikings. The blood samples were collected in lead-free evacuated blood-collection tubes (Venoject). Reference blood was obtained from nonexposed blood donors. All extracts and standard solutions were stored in lead-free glass vials with screwcaps and kept at $-20^{\circ} \mathrm{C}$. All glassware was washed with detergent, soaked in nitric acid, and rinsed several times in purified water before use.

\section{Instrumentation}

A Pye Unicam GCD, fitted with a Unijector (Scientific Glass Engineering) in the Grob splitless injection mode, was used for the GC separations. The injection time for the splitless injector was controlled by an electronic module, capillary injector Mark 2, supplied by Philips (Stockholm, Sweden). This module was modified in order to allow a simultaneous start of all time dependent parameters. Thus the splitless injection time, the GC oven temperature programmer, and the atomization cycle were all triggered at the same time.

The AAS determinations were performed with either a Pye Unicam SP 1900 fitted with a quartz cuvette mounted on the burner head or a Pye Unicam

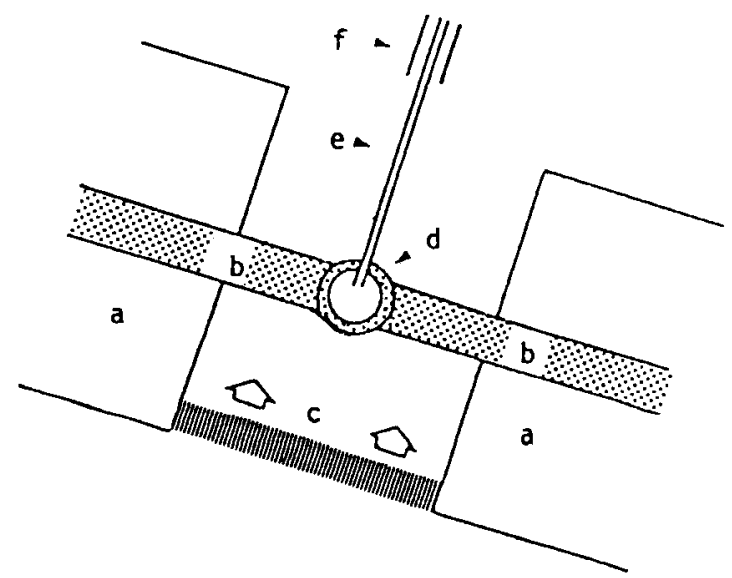

Figure 1. Schematic figure (cross-section) of the fused silica column connection to the graphite tube in the Varian CRA 90 graphite furnace. ( $a=$ body of the Varian CRA 90 , $\mathrm{b}=$ graphite electrodes, $\mathrm{c}=$ nitrogen shield gas, $\mathrm{d}=$ graphite tube, $e=$ fused silica column, $f=$ copper tubing, for protection of the capillary column, and dotted area = graphite parts)
SP 192 and a Varian CRA 90 graphite furnace with an optical temperature control. The water cooling system in the graphite furnace was modified to enable atomization times of up to $10 \mathrm{~min}$. Some modification was also made in the atomization tube. A $0.45-\mathrm{mm}$ hole was drilled as an inlet port at $90^{\circ}$ to the injection port, which was then covered by one of the electrodes. For the packed columns (inner diameter approximately $6 \mathrm{~mm}$ ) the line between the gas chromatograph and the atomic absorption spectrophotometer was a $30-\mathrm{cm}$ glass-lined metal tubing (inner diameter approximately $0.3 \mathrm{~mm}$ ). The tubing was connected to the end of the column and fitted through a septum into the quartz cuvette near the light beam.

The fused silica columns were led through a $50-\mathrm{cm}$ copper tubing (inner diameter approximately $3 \mathrm{~mm}$ ) from the detector port on the gas chromatograph over to the graphite furnace. The end of the column was fitted into the $0.45-\mathrm{mm}$ inlet port in the atomization tube (figure 1).

For the analysis of tetramethyllead, an OV-101 fused silica column (length $50 \mathrm{~m}$, inner diameter $0.3 \mathrm{~mm})$ was used. Hydrogen $(5 \mathrm{ml} / \mathrm{min})$ was used as the carrier gas. A 2- $\mu$ l aliquot of the heptane extracts was injected in the Grob splitless injection system. The injection temperature was $70^{\circ} \mathrm{C}$, and an injection time of $30 \mathrm{~s}$ was used. The oven temperature was $80^{\circ} \mathrm{C}$ isothermal.

For the AAS detection, an electrodeless discharge lamp was operated at $217 \mathrm{~nm}$ with an effect of $13 \mathrm{~W}$. Background correction was necessary, and the standard deuterium-lamp system in the SP 192 was sufficient. The dry step of the graphite furnace cycle, $120-150 \mathrm{~s}$, was kept below $100^{\circ} \mathrm{C}$ as a standby step. Ashing step I, $30 \mathrm{~s}$, was used as a ramp to the atomization temperature at $1,100^{\circ} \mathrm{C}$. During ashing step II, $10 \mathrm{~s}$, the autozero function of the integration device was operating. The integration was then performed throughout the atomization step, lasting 10-60 s. For the determinations of inorganic lead, the Pye Unicam SP 192 and the Varian CRA 90 graphite furnace were used with the GC system disconnected. The analytical method of Nise \& Vesterberg (10) was used.

\section{Extraction procedure}

Blood samples or spiked reference blood were hemolyzed by freezing at $-20^{\circ} \mathrm{C}$ for $24 \mathrm{~h}$. A $4-$ to $8-\mathrm{ml}$ aliquot from each sample or reference was extracted with $2 \mathrm{ml}$ of $\mathrm{n}$-heptane in an ultrasonic bath for 20 min. A 4-ml aliquot of the sample or reference was generally sufficient. In the same analytical series, both samples and references were extracted from the same volume. The samples were then centrifuged at $5,000 \mathrm{r} / \mathrm{min}$ to facilitate phase separation. The organic layer was withdrawn and kept at $-20^{\circ} \mathrm{C}$ in screwcap vials until required for analysis. 


\section{Results and discussion}

As pointed out in the introduction section, GC-AAS fulfills some main requirements for a reliable method analyzing alkyllead compounds. First, the detection system, AAS, is specific, and background from organics in the sample is thus avoided. Second, as discussed later, the sensitivity can be optimized to a sufficient level. Third, the GC separation further increases the specificity of the analysis. The first step in evaluating proper instrumental setup was to repeat some of the main instrumental arrangements described in the literature. Table 1 shows the detection limits achieved with various GC-AAS systems. The detection limits were normalized to a $2-\mu \mathrm{l}$ injection of a solvent extract so as to make a comparison possible.

As can be seen, the fused silica column gave better results than the packed column when connected to the same detection system, ie, AAS with a quartz cuvette. An even better detection limit was achieved with a graphite furnace coupled to the same GC column. Thus, in this study, the high-resolution GCgraphite-furnace AAS (HRGC-GFAAS) system was found to give the highest sensitivity. The performance of a capillary column ensures maximum separation and thus minimizes the risk of interference due to high background from coeluting compounds.

\section{Instrumental arrangement}

Tetramethyllead is the dominant antiknock additive in gasoline in Sweden today. Accordingly work was initially concentrated on finding the optimum parameters for the analysis of tetramethyllead. Various column phases have been used for the chromatographic separation of organolead compounds (5). Fused silica columns with different stationary phases, SP 1000 , OV-101, and Carbowax $20 \mathrm{M}$, were investigated in our study. OV-101, giving a short retention time for tetramethyllead and an adequate separation, was found to be the best column for this application. It was found that the flow rate of the carrier gas was too low in fused silica columns with an inner diameter of $0.20-0.25 \mathrm{~mm}$. These columns burned out next to the graphite tube, broke, and started leaking. A high enough flow rate was attained with columns with an inner diameter of $0.3 \mathrm{~mm}$. It was also necessary to increase the flow rate of the carrier gas in order to obtain a rapid AAS signal. The best signal was obtained at a flow rate of $5 \mathrm{ml} / \mathrm{min}$, which is far above the minimum of the van Deemter plot (8). Since hydrogen is used as the carrier gas and since the van Deemter plot for this gas is very flat at higher gas flows, it is possible to use such a high flow rate.

Standard GC conditions were used during the optimization of the AAS parameters. An atomization curve was plotted showing the signal maximum as early as $1,000^{\circ} \mathrm{C}$. An electrodeless discharge lamp gave a signal-to-noise ratio that was more than five times better than a hollow cathode lamp. Background correction was necessary because of the organic compounds present.

One of the main problems with arrangements of this kind is optimization of the parameters in order to decrease the atomization time to a minimum. Such optimization is necessary for the following two reasons: (i) the risk of the furnace overheating and (ii) the decreased lifetime of the graphite parts of the furnace.

The electronic start module was modified so that the time-dependent parameters, ie, injection time, column temperature program, and graphite furnace cycle, could be synchronized. This module made it possible to adjust carefully the graphite furnace cycle versus the retention time of tetramethyllead so that the atomization time was minimized. Although the atomization time was minimized, it was necessary to modify the water cooling system in the graphite furnace. All gaskets were replaced by Teflon gaskets, and the water flow was increased to $3 \mathrm{l} / \mathrm{min}$. These modifications made 10 -min atomization periods possible. With the described modifications, the lifetime of the graphite tubes was at least $\mathbf{5 0}$ atomizations. The integration times became shorter thus giving a higher accuracy of integration of the tetramethyllead signal.

\section{Extraction procedure}

The first step in the proposed procedure is the extraction of the organolead compounds from the sample. Benzene (1) and hexane (2) have been used by others.

To find an appropriate solvent for the whole analytical procedure, we investigated six solvents $-\mathrm{di}$ ethyl ether, hexane, heptane, benzene, undecane, and dichloromethane. Heptane was found to combine a suitable volatility for splitless injection and good extractive properties to give an optimum sensitivity. The overall sensitivity attained with the use of

Table 1. Detection limits for tetramethyllead, as found in this study, with various instrumental arrangements. The detection limits are normalized to a $2-\mu$ l injection of a solvent extract.

\begin{tabular}{cc}
\hline Arrangement & $\begin{array}{c}\text { Detection } \\
\text { limit } \\
(\mu \mathrm{g} / \mathrm{ml})\end{array}$ \\
\hline
\end{tabular}

Gas chromatography, packed column atomic absorption spectrophotometry, direct in the flame

Gas chromatography, packed column atomic absorption spectrophotometry, quartz cuvette in the flame

Gas chromatography, capillary column atomic absorption spectrophotometry, quartz cuvette in the flame

Gas chromatography, capillary column atomic absorption spectrophotometry, graphite furnace 
Table 2. Extraction test of tetramethyllead from spiked blood samples (solvent n-heptane) - Mean of three samples.

\begin{tabular}{lccc}
\hline $\begin{array}{l}\text { Tetramethyllead } \\
\text { added } \\
(\mu \mathrm{g} / \mathrm{ml})\end{array}$ & \multicolumn{3}{c}{ Recovery } \\
\cline { 2 - 4 } & $\begin{array}{c}\text { Mean } \\
(\mu \mathrm{g} / \mathrm{ml})\end{array}$ & $\%$ & $\begin{array}{c}\text { Range } \\
(\mu \mathrm{g} / \mathrm{ml})\end{array}$ \\
\hline 0.100 & 0.093 & 93 & $0.092-0.094$ \\
0.050 & 0.046 & 92 & $0.045-0.047$ \\
0.020 & 0.019 & 95 & $0.018-0.019$ \\
0.010 & 0.009 & 90 & $0.008-0.009$ \\
\hline
\end{tabular}

Table 3. Tetramethyllead in occupational blood samples.

\begin{tabular}{lcc}
\hline Sample $^{\mathrm{a}}$ & $\begin{array}{c}\text { Inorganic } \\
\text { lead } \\
(\mu \mathrm{g} / \mathrm{ml})\end{array}$ & $\begin{array}{c}\text { Tetramethyllead } \\
(\mathrm{as} \text { lead }) \\
(\mu \mathrm{g} / \mathrm{ml})\end{array}$ \\
\hline $\mathrm{A}$ & 0.26 & 0.027 \\
$\mathrm{~B}$ & 0.12 & 0.018 \\
$\mathrm{C}$ & 0.12 & 0.010 \\
$\mathrm{D}$ & 0.08 & 0.006 \\
$\mathrm{E}$ & 0.06 & 0.005 \\
$\mathrm{~F}$ & 0.04 & 0.005 \\
$\mathrm{G}$ & 0.04 & 0.005 \\
$\mathrm{H}$ & 0.08 & 0.006 \\
I & 0.10 & 0.005 \\
Reference group & 0.08 & $<0.003$ \\
\hline
\end{tabular}

a $\mathrm{A}-\mathrm{C}$ were tank cleaners; $\mathrm{D}-\mathrm{I}$ were gasoline pump servicemen; the reference group was comprised of five subjects, all $<0.003 \mu \mathrm{g} / \mathrm{ml}$.

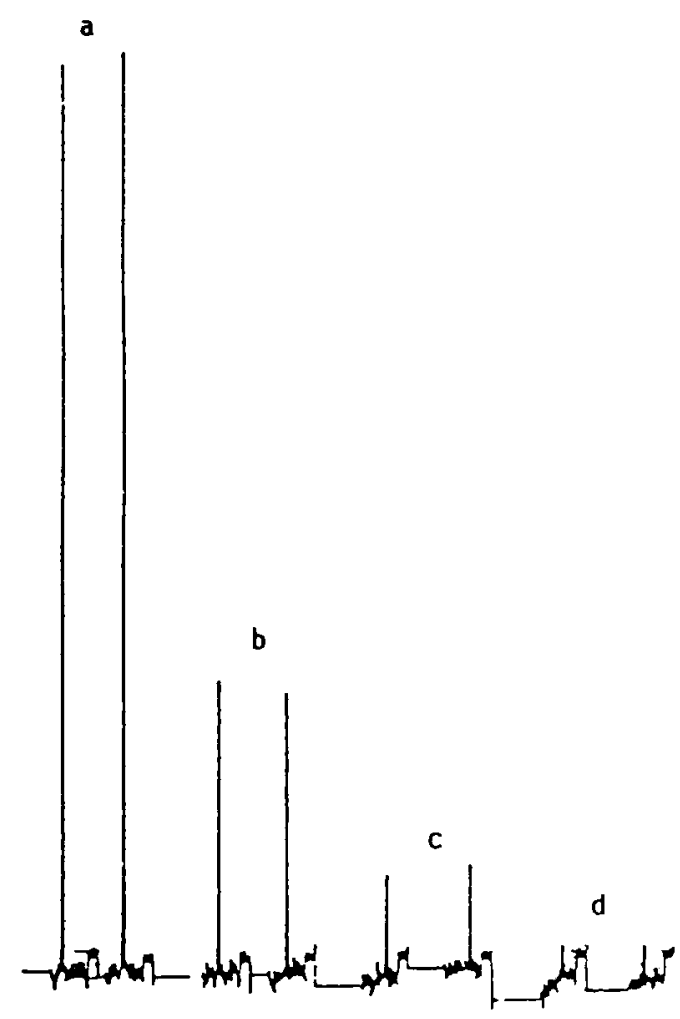

Figure 2. Typical chromatographs of tetramethyllead extracted from blood samples. Duplicate $2-\mu$ l injections were made, and the recorder was on only during the atomization time, $50 \mathrm{~s}$. $(a=0.40, b=0.10, c=0.04$, and $d=0.01 \mu \mathrm{g} / \mathrm{ml}$ in heptane) heptane was twice that attained with the next best solvent, hexane. Reference blood samples were spiked with different amounts of tetramethyllead. The samples and controls were hemolyzed by freezing, and a 4-ml aliquot was extracted with $2 \mathrm{ml}$ of heptane. After centrifugation, the organic layer was removed and analyzed. The tetramethyllead concentration was compared with working standards in heptane. Table 2 shows the results of the extraction tests; the recovery was more than $90 \%$ in the $0.01-$ to $0.10-\mu \mathrm{g} / \mathrm{ml}$ interval with a relative standard deviation of less than $10 \%$.

In figure 2 some typical chromatograms of tetramethyllead extracted from spiked blood samples are shown. As can be seen, there were no disturbances in the chromatograms, and only lead was detected.

\section{Tetramethyllead in blood samples from exposed workers}

Blood samples were collected from three tank cleaners and six gasoline pump servicemen. The latter were exposed to liquid gasoline as well as gasoline vapor while servicing gasoline pumps. The tank cleaners worked inside gasoline cisterns and were thus exposed to very high levels of gasoline vapor in the air. The samples were analyzed for inorganic lead with the use of a standard method with GFAAS (10) and for tetramethyllead with the method proposed in the present report. The results, presented in table 3, did not show any increased values of inorganic lead except for one subject, although all nine had detectable amounts of tetramethyllead in the blood. The reference group did not show any detectable tetramethyllead. It was also evident that the tank cleaners had higher levels of tetramethyllead than the servicemen.

There is however little medical data available in the literature. Therefore it is not possible to draw any wider conclusions regarding the significance of the tetramethyllead levels found.

As mentioned earlier, there is also a possibility of biotransformation of tetraalkyllead in the body (6). This possibility further complicates the picture and makes an interpretation of the results even more difficult. Refinements of the analytical method are in progress to take account of the metabolites.

\section{Conclusions}

The developed method can be used for the analysis of tetraalkyllead in nanogram per millimetre levels in blood with a recovery exceeding $90 \%$. It has been applied for the analysis of tetramethyllead in blood samples from occupationally exposed subjects. 


\section{Acknowledgments}

We are grateful for the reference blood supplied by Dr B Cedergren and his staff at the blood bank at the University Hospital of Umeå. We also wish to thank the occupational health centers at Vännäs and Stockholm for collecting blood samples from exposed workers.

\section{References}

1. Bolanowska W. Distribution and excretion of triethyllead in rats, $\mathrm{Br} \mathrm{j}$ ind med 25 (1968) 203-208.

2. Chau YK, Wong PTS, Bengert GA, Kramar O. Determination of tetraalkyllead compounds in water, sediment and fish samples. Anal chem 51 (1979) 186-188.

3. Coker DT. A simple, sensitive technique for personal and environmental sampling and analysis of lead alkyl vapours in air. Ann occup hyg 21 (1978) 33-38.

4. Cruz RB, Lorouso C, George S, Thomassen Y, Kinrade JD, Butler LRP, Lye J, Van Loon JC. Determination of total, organic solvent extractable, volatile and tetraalkyllead in fish, vegetation, sediment and water samples. Spectrochim acta 35B (1980) 775-783.
5. DeJonghe WRA, Adams FC. Measurements of organic lead in air - A review. Talanta 29 (1982) 1057-1067.

6. Grandjean P, Nielsen T. Organolead compounds: Environmental health aspects. Residue rev 72 (1979) 97-148.

7. Hayakawa K. Microdetermination and dynamic aspects of in vivo alkyllead compounds: I Analytical methods. Jpn j hyg 26 (1971) 377-385.

8. McNair HM, Bonelli EJ. Basic gas chromatography. Fifth edition. Varian Instrument Division Office, Palo Alto, CA 1969.

9. Messman JD, Rains TC. Determination of tetraalkyllead compounds in gasoline by liquid chromatography - Atomic absorption spectrometry. Anal chem 53 (1981) 1632-1636.

10. Nise $G$, Vesterberg $O$. Blood lead determination by flameless atomic absorption spectroscopy. Clin chim acta 84 (1978) 129-136.

11. Wong PTS, Chau YK, Kramar O, Bengert GA. Accumulation and depuration of tetramethyllead by rainbow trout. Water res 15 (1981) 621-625.

Received for publication: 4 October 1983 